\title{
Effect of Sn Doping on the Properties of ZnO Thin Films Prepared by Spray Pyrolysis
}

\author{
Nadia Chahmat ${ }^{1}$, Ammar Haddad ${ }^{1}$, Azzedine Ain-Souya ${ }^{1}$, Rachid Ganfoudi ${ }^{1}$, \\ Nadir Attaf ${ }^{2}$, Mouhamed Salah Aida ${ }^{2}$, Mokhtar Ghers ${ }^{1}$ \\ ${ }^{1}$ Laboratory of Surfaces and Interfaces (LESIMS), Department of Physics, Faculty of Science, \\ University Badji Mokhtar of Annaba, Annaba, Algeria \\ ${ }^{2}$ Laboratory of Thin Films Surfaces and Interface, Faculty of Science, Department of Physics, \\ University Mentouri of Constantine, Constantine, Algeria \\ Email: chahmatsou@yahoo.fr
}

Received July 26, 2012; revised September 3, 2012; accepted September 28, 2012

\begin{abstract}
Layers of transparent and conductive Sn-doped zinc oxide $(\mathrm{ZnO})$ have been prepared using chemical reactive liquid phase (spray) method on glass substrates. X-ray diffraction analysis shows that the obtained layers show preferential grains orientation along the direction (002). Microstructural analysis indicates that the thickness of the deposited films is independent of $\mathrm{Sn}$ content, i.e. $408 \mathrm{~nm}$, and that the average grain size increases with increasing Sn content, ranging from $31 \mathrm{~nm}$ to $42 \mathrm{~nm}$. The value of the optical gap obtained using UV-visible transmission spectroscopy method increases slightly from $3.1 \mathrm{eV}$ to $3.3 \mathrm{eV}$. Moreover, transmission curves reveal that the prepared thin films are transparent in the visible domain.
\end{abstract}

Keywords: ZnO Thin Films; Ultrasonic Spray; Semiconductor Doping; Optical Gap

\section{Introduction}

Due to the excellent structural and optical properties, zinc oxide $(\mathrm{ZnO})$ thin films have wide applications as solar cells [1], gas sensors [2], light emitting diodes (LED's), laser systems [3] and transparent electrodes [4]. Moreover, they can be prepared by different techniques, such as magnetron sputtering [5], reactive evaporation [6], chemical vapor deposition (CVD) [7], pulsed laser deposition (PLD) [8] and spray pyrolysis [9].

Among these methods, the spray pyrolysis technique has several advantages, such as, simplicity, safety, and low cost of the apparatus and raw materials.

Zinc oxide is a semiconductor with a direct large gap and generally, crystallizes in würtzite structure [10]. However, the size, the orientation of grains and the surface quality depend on the conditions in which the material was prepared and the different treatments which can be made. Indeed, surface states of semiconductor materials generate superficial electronic properties which are often significantly affected by their interactions with foreign elements.

In the present study, we have investigated the effect of a larger Sn doping ratio range (up to $10 \%$ ) on the structural and optical properties of tin doped zinc oxide thin films deposited by ultrasonic spray. Moreover, $\mathrm{ZnO}$ thin films were deposited by ultrasonic spray technique with a non aqueous starting solution [11].

There have been extensive studies on the crystalline structure, optical transmittance of doped $\mathrm{ZnO}$ thin films prepared by spray pyrolysis methods [12]. There are, however, few studies on optical constants, and absorption coefficient of doped $\mathrm{ZnO}$ thin films. In this paper, we study the effect of different $\mathrm{Sn}$ percentages on the structural and optical properties of $\mathrm{ZnO}$ thin films deposited by spray pyrolysis.

\section{Experimental}

The films were grown onto glass substrates, using a typical spray pyrolysis system. The starting solution is composed with 0.1 molarity of zinc acetate ( $\mathrm{Zn}$ $\left.(\mathrm{CH} 3 \mathrm{COO})_{2} \cdot 2 \mathrm{H}_{2} \mathrm{O}\right)$ salt diluted in methanol. Sn doping is achieved by adding a small quantity of $\left(\mathrm{SnCl}_{2} \cdot 2 \mathrm{H}_{2} \mathrm{O}\right)$ in the solution. The weight of the added doping source is calculated as function of the desired $\mathrm{Sn} / \mathrm{Zn}$ ratio. The latter was varied in the range of $0 \%-10 \%$. The prepared solution is then sprayed on the heated glass substrates by ultrasonic nebulizer system (Sonics) which transforms the liquid to a stream formed with uniform and fine droplets of $40 \mu \mathrm{m}$ average diameter (given by the manufacturer). The temperature of the substrates was $350^{\circ} \mathrm{C}$. 
The spray pyrolysis method is one of the most commonly used methods for preparation of transparent and conducting oxides owing to its simplicity, safety, nonvacuum system of deposition and hence inexpensive method. Other advantages of the spray pyrolysis method are that it can be adapted easily for production of largearea films, and to get varying band gap materials during the deposition process.

The crystalline structure was studied by X-ray diffraction measurements using a Brucker D8 Advance diffractometer with $\mathrm{Cu} \mathrm{K} \alpha$ radiation $(\lambda \mathrm{Cu}=0.154056 \mathrm{~nm})$. The diffractometer reflections were taken at room temperature and the value of $2 \theta$ were swapped between $20^{\circ}$ and $70^{\circ}$. The optical transmission measurements were performed with a (UV-3101 PC-SHIMADZU) UV-Visible spectrophotometer. The thickness of the films was calculated from optical transmission by interference method.

\section{Results and Discussion}

\subsection{Structural Properties}

Figure 1 shows the spectra of X-ray diffraction for thin films of Sn doped and undoped. The peaks of X-ray diffraction indicate that all obtained films are polycrystalline with hexagonal wurtzite structure and a preferential orientation of $\mathrm{c}$ axis perpendicular to the substrate. There was no significant difference for the films undoped and Sn doped. Both kinds of spectra represent the dominant peak (002) which is located $2 \theta=34.09^{\circ}$ and $34.55^{\circ}$, respectively. Authors attribute this shift to the substitution of zinc and tin in the hexagonal structure. This result is in good agreement with literature data [13-15]. Another major orientation present is (100) and (101) are also seen in Figure 1.

It is also evident in Figure 1 that the preferential (002) peak intensity increases with increasing Sn dopant concentration. This indicates an improvement in films crys-

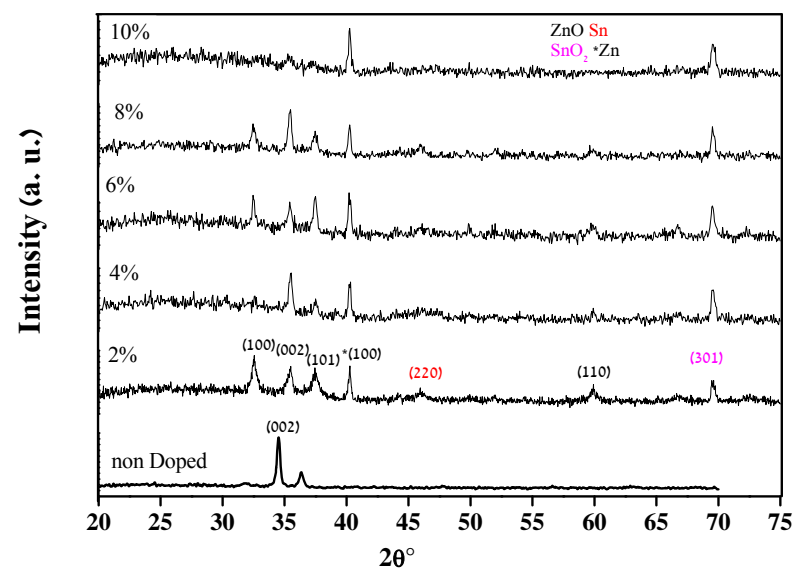

Figure 1. X-ray diffraction spectra of un-doped and Sn doped $\mathrm{ZnO}$ thin films. tallinity with $\mathrm{Sn}$ film doping. However, for concentrations above $8 \%$ the films crystallinity is degraded [16] with Sn doping and the preferential orientation are changed from (002) to (101) and (100) $[17,18]$. This discrepancy may be due to the difference in the surface reactions.

The grain size of crystallites was calculated using a well-known Scherrer's formula [19]:

$$
D=0.9 \lambda / \beta \cos \theta
$$

where $D$ is the grain size of crystallite, $\lambda(=1.54059 \AA)$ the wavelength of X-rays used, $\beta$ the broadening of diffraction line measured at half its maximum intensity in radians and $\theta$ is the angle of diffraction. The values of grain size are found to be $31 \mathrm{~nm}$ to $41.37 \mathrm{~nm}$ for $\mathrm{Sn}$ doped $\mathrm{ZnO}$ and $29 \mathrm{~nm}$ for $\mathrm{ZnO}$ non doped thin films. Figure 2 shows the variation of the grain size calculated from the X-ray diffraction patterns as mentioned in experimental section. The grain size of the films increases with different introduced percentages of the Sn.

\subsection{Optical Properties}

The optical properties of thin films of $\mathrm{ZnO}$ undoped and doped Sn was determined from the transmission measurement in the range of $300-800 \mathrm{~nm}$. Figure 3 shows the optical transmission of the doped films deposited onto the glass substrates. The transmission of the films changes with the Sn percentage doping. The properties of the films vary with the percentage of the doping element and this causes light loss on the films. Thus, the changes in the transmission take place. The fundamental absorption edge of the films corresponds to electron transitions from valence band to conduction band and this edge can be used to calculate the optical band gap of the films. The transmission decreases slightly when the percentage of $\mathrm{Sn}$ increases. All films show a high transmission in the $\mathrm{UV}-\mathrm{V}$ is and with a sharp absorption edge at $380 \mathrm{~nm}$.

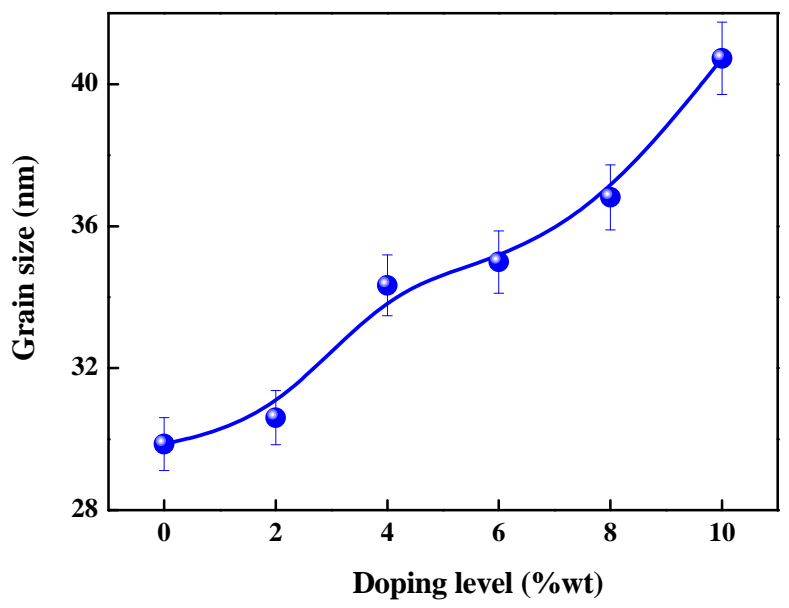

Figure 2. Variation of grain size with doping level. 


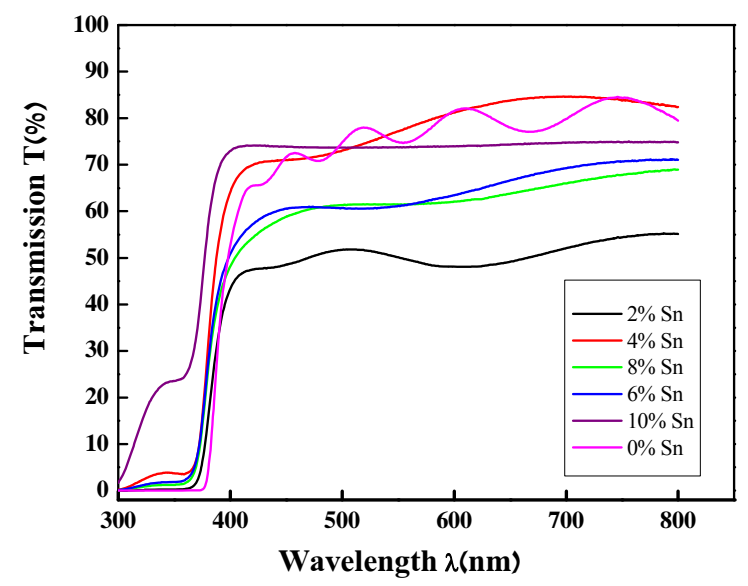

Figure 3. The transmittance spectra of un-doped and Sn doped $\mathrm{ZnO}$ thin films.

The absorption coefficient $\alpha$ of $\mathrm{ZnO}$ films was determined from transmittance measurements. The films absorption coefficient was calculated using the following expression:

$$
\alpha=-(1 / \mathrm{d}) \ln (T)
$$

where $T$ is the normalized transmittance and $\mathrm{d}$ is the film thickness. These absorption coefficient values were used to determine optical energy gap. The energy gap $(E g)$ was estimated by assuming a direct transition between valence and conduction bands from the expression:

$$
(\alpha h v)=A(h v-E g)^{1 / 2}
$$

where $A$ is a constant, $h v$ is the photon energy and $E g$ is the optical band. Figure 4 shows plots of $(\alpha h v)^{2}$ versus $(h v)$. The optical band gap of the films was calculated from these plots.

The Optical energy gap was derived assuming a direct transition between the edges of the valence band and the conduction band. The plot of $(\alpha h v)^{2}$ versus $(h v)$ gives by extrapolation of the linear region of the resulting curve the optical band gap value.

The calculated optical gap of samples increases with increasing the percentage of Sn from $3.256 \mathrm{eV}$ for undoped $\mathrm{ZnO}$ films to $3.3 \mathrm{eV}$ for $\mathrm{ZnO}$ doped $\mathrm{Sn}$. This shift of absorption of nanocrystalline films of $\mathrm{ZnO}$ doped $\mathrm{Sn}$ can be explained by the Burstein-Moss effect [20] while assuming the increase in carrier concentration that blocks the lowest states in the conduction band.

The absorption coefficient of films shows a tail for subband gap photon energy; this tail is so-called Urbach tail. The latter, which is closely related to the disorder in the film network, is expressed as [20]:

$$
\alpha=\alpha_{0} \exp \left(h v / E_{U}\right)
$$

where $\alpha_{0}$ is a constant, $E_{U}$ is the Urbach energy, which characterizes the slope of the exponential edge. The above equation describes the optical transition between occupied state in the valence band tail to unoccupied state of the conduction band edge. Figure 5 shows Urbach plots of the films. The value of $E_{U}$ was obtained from the inverse of the slope of $\ln \alpha$ versus $(h v) . E_{U}$ values change inversely with optical band gap.

Figure 6 shows the variations of the optical gap together with the Urbach tail energy as a function of $\mathrm{Sn}$ doping level. It is clear that the optical gap is reduced with Sn doping. This band gap narrowing is due to the increase in the band tail width as shown in Figure 6. It is worth to bear in mind that the Urbach tail energy is closely related to the disorder in the film network. Since the ion radius of $\mathrm{Sn}$ is larger than $\mathrm{Zn}$ [20], the Sn introduction into the films is then followed by the lattice distortion and consequently disorder creation which cause the optical reduction. The same conclusion has been reported by A. Hafdallah et al. [11] in In doped ZnO.

The optical gap increases with the Sn doping concentration up to the percentage of $8 \%$. Above this doping level, the gap value decreases. This shows that the percentage of $8 \%$ is the solubility limit of $\mathrm{Sn}$ in $\mathrm{ZnO}$.

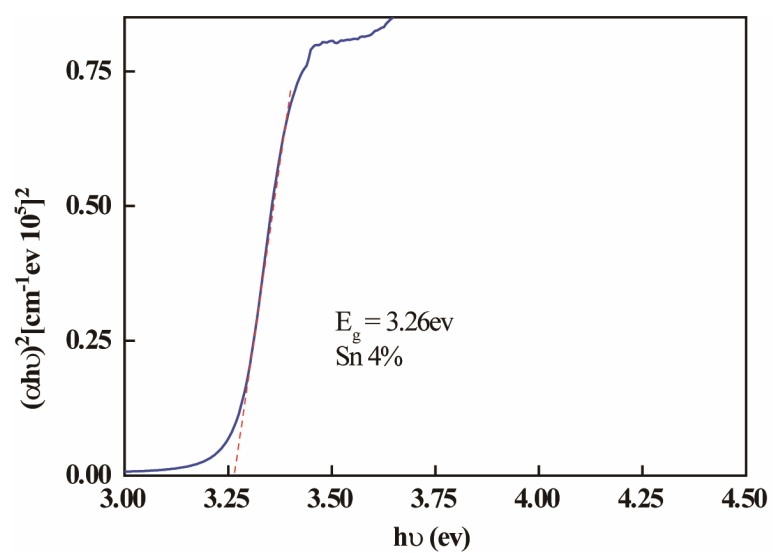

Figure 4. The plots of $(\alpha h v)^{2}$ as function of photon energy of the $\mathrm{ZnO}$ doped $\mathrm{Sn}$.

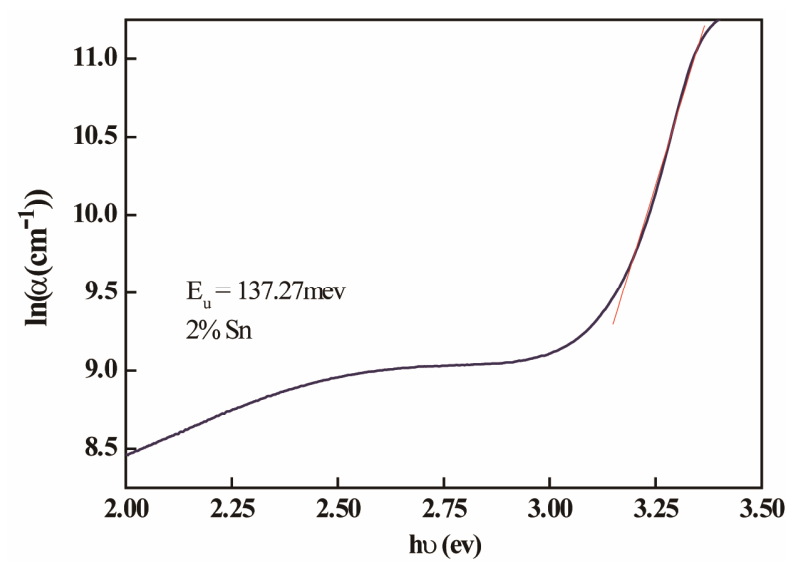

Figure 5. The Urbach plots of the doped thin $\mathrm{ZnO}$. 


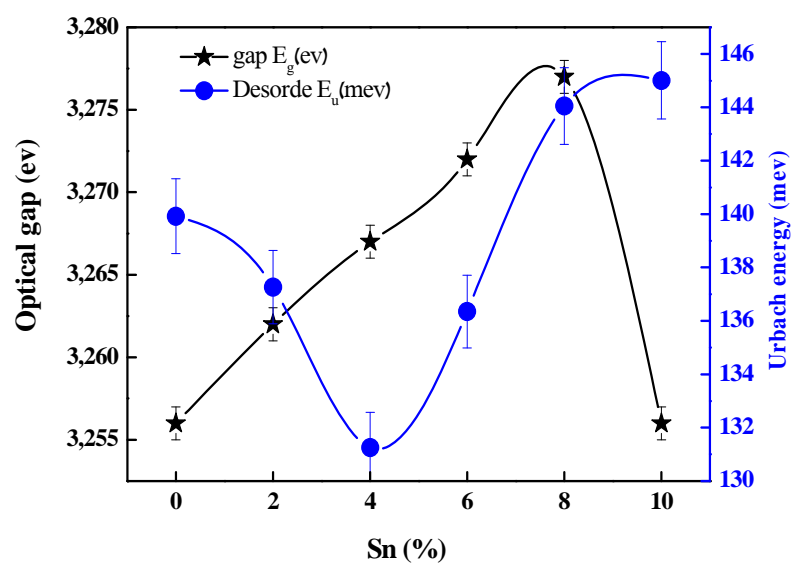

Figure 6. The effect Sn dopant on optical band gap and Urbach energy of the films.

\section{Conclusions}

$\mathrm{ZnO}$ thin films were deposited by ultrasonic spray technique with a non aqueous solution. The effect of Sn concentration on the structural and optical properties of films was investigated. The deposited films of $\mathrm{ZnO}$ undoped and doped Sn showed that the films have polycrystalline structure witch preserve their (002) preferential orientation. The grain sizes increased depending on the increasing Sn concentration.

The optical transmission increases and becomes important for $\lambda>380 \mathrm{~nm}$, which proves that the $\mathrm{ZnO}$ thin films Sn doped have an excellent transparency in the visible game while the optical gap is reduced with increasing in $\mathrm{Sn} / \mathrm{Zn}$ doping ratio. This is linked to the dis $\mathrm{r}$ with incorporation $\mathrm{Sn}$ in the film.

The optical gap of $\mathrm{ZnO}$ films increases with the percentage of Sn doping. When the limit of $8 \%$ doping is reached, the gap is reduced.

\section{REFERENCES}

[1] J. B. Baxter and E. S. Aydil, "Dye-Sensitized Solar Cells Based on Semiconductor Morphologies with ZnO Nanowires," Solar Energy Materials and Solar Cells, Vol. 90, No. 5, 2006, pp. 607-622. doi:10.1016/j.solmat.2005.05.010

[2] S. T. Shishiyanu, T. S. Shishiyanu and O. I. Lupan, "Sensing Characteristics of Tin-Doped ZnO Thin Films as $\mathrm{NO}_{2}$ Gas Sensor," Sensors and Actuators B: Chemical, Vol. 107, No. 1, 2005, pp. 379-386. doi:10.1016/j.snb.2004.10.030

[3] J. M. Szarko, J. K. Song, B C. W. lackledge, I. Swart, S. R. Leone, S. Li, et al., "Optical Injection Probing of Single ZnO Tetrapod Lasers," Chemical Physics Letters, Vol. 404, No. 1-3, 2005, pp. 171-176. doi:10.1016/j.cplett.2005.01.063

[4] T. Ootsuka, Z. Liu, M. Osamura, Y. Fukuzawa, R. Kuroda, Y. Suzuki, et al., "Studies on Aluminum-Doped $\mathrm{ZnO}$ Films for Transparent Electrode and Antireflection
Coating of $\beta-\mathrm{FeSi}_{2}$ Optoelectronic Devices," Thin Solid Films, Vol. 476, No. 1, 2005, pp. 30-34.

doi:10.1016/j.tsf.2004.06.145

[5] X. Yu, J. Ma, F. Ji, Y. Wang, X. Zhang and H. Ma, "Influence of Annealing on the Properties of $\mathrm{ZnO}$ : Ga Films Prepared by Radio Frequency Magnetron Sputtering," Thin Solid Films, Vol. 483, No. 1-2, 2005, pp. 296-300. doi:10.1016/j.tsf.2005.01.013

[6] J. Ma, F. Ji, D. Zhang, H. Ma and S. Li, "Optical and Electronic Properties of Transparent Conducting $\mathrm{ZnO}$ and ZnO: Al Films Prepared by Evaporating Method," Thin Solid Films, Vol. 357, No. 2, 1999, pp. 98-101. doi:10.1016/S0040-6090(99)00357-0

[7] D. A. Lamb and S. J. C. Irvine, "Growth Properties of Thin Film ZnO Deposited by MOCVD with n-Butyl Alcohol as the Oxygen Precursor," Journal Crystal Growth, Vol. 273, No. 1-2, 2004, pp. 111-117. doi:10.1016/j.jcrysgro.2004.08.027

[8] J. Zou, S. Zhou, C. Xia, Y. Hang, J. Xu, S. Gu, et al., "Structural Optical and Electrical Properties of $\mathrm{ZnO}$ Films Grown on c-Plane Sapphire and $\left(\begin{array}{lll}1 & 0 & 0\end{array}\right) \gamma-\mathrm{LiAlO}_{2}$ by Pulse Laser Deposition," Journal Crystal Growth, Vol. 280, No. 1-2, 2005, pp. 185-190. doi:10.1016/j.jcrysgro.2005.03.036

[9] P. Nunes, E. Fortunato, P. Tonello, F. Braz Fernandez, P. Vilarinho and R. Martins, "Effect of Different Dopant Elements on the Properties of $\mathrm{ZnO}$ Thin Films," Vacuum, Vol. 64, No. 3-4, 2002, pp. 281-285. doi:10.1016/S0042-207X(01)00322-0

[10] A. A. EL-Fadl, G. A. Mohamed, A. B. Abd EL-Moiz and M. Rashad, "Optical Constants of $\mathrm{Zn}_{1-x} \mathrm{Li}_{x} \mathrm{O}$ Films Prepared by Chemical Bath Deposition Technique," Physica B: Condensed Matter, Vol. 366, No. 1-4, 2005, pp. 44-54.

[11] A. Hafdallah, F. Yanineb, M. S. Aida and N. Attaf, "In Doped ZnO Thin Films," Journal of Alloys and Compounds, Vol. 509, No. 26, 2011, pp. 7267-7270. doi:10.1016/i.jallcom.2011.04.058

[12] M. A. Lucio-Lópeza, M. A. Luna-Arias, A. Maldonado, M. de la L. Olvera and D. R. Acosta, "Preparation of Conducting and Transparent Indium-Doped ZnO Thin Films by Chemical Spray," Solar Energy Materials and Solar Cells, Vol. 90, No. 6, 2006, pp. 733-741. doi:10.1016/j.solmat.2005.04.010

[13] Y. Caglar, S. Ilican, M. Caglar and F. Yakuphanoglu, "Effects of Al and Sn Dopants on the Structural and Optical Properties of ZnO Thin Films," Spectrochimica Acta Part A, Vol. 67, No. 3-4, 2007, pp. 1113-1119.

[14] J.-H. Lee and B.-O. Park, "Characteristics of Al-doped ZnO Thin Films Obtained by Ultrasonic Spray Pyrolysis Effects of Al Doping and an Annealing Treatment," Thin Solid Films, Vol. 426, No. 1-2, 2003, pp. 94-99. doi:10.1016/S0040-6090(03)00014-2

[15] Z.-Q. Xu, H. Deng, Y. Li and H. Cheng, "Al-Doping Effects on Structure, Electrical and Optical Properties of c-Axis-Orientated ZnO: Al Thin Films," Materials Science in Semiconductor Processing, Vol. 9, No. 1-3, 2006, pp. 132-135. doi:10.1016/j.mssp.2006.01.082

[16] S. Ilican, Y. Caglar, M. Caglar and B. Demirci, "Polycrystalline Indium-Doped $\mathrm{ZnO}$ Thin Films: Preparation 
and Characterization," Journal of Optoelectronics and Advanced Materials, Vol. 10, No. 10, 2008, pp. 25922598

[17] S. Ilican, Y. Caglar, M. Caglar and F. Yakuphanoglu, "Electrical Conductivity, Optical and Structural Properties of Indium-Doped ZnO Nanofiber Thin Film Deposited by Spray Pyrolysis Method," Physica E: Low-Dimensional Systems and Nanostructures, Vol. 35, No. 1, 2006, pp. 131-138. doi:10.1016/i.physe.2006.07.009

[18] M. A. Kaid and A. Ashour, "Preparation of ZnO-Doped Al Films by Spray Pyrolysis Technique," Applied Surface
Science, Vol. 253, No. 6, 2007, pp. 3029-3033. doi:10.1016/j.apsusc.2006.06.045

[19] B. D. Cullity and S. R. Stock, "Elements of X-Ray Diffraction," 3rd Edition, Prentice Hall, Upper Saddle River, 2001.

[20] F. Paraguay, W. Estrada, D. R. Acosta, E. Andrade and M. Miki-Yoshida, "Growth, Structure and Optical Characterization of High Quality ZnO Thin Films Obtained by Spray Pyrolysis," Thin Solid Films, Vol. 350, No. 1-2, 1999, pp. 192-202. doi:10.1016/S0040-6090(99)00050-4 